\title{
(2) OPEN ACCESS \\ Can a patient-directed video improve inpatient advance care planning? A prospective pre-post cohort study
}

\author{
Rajesh Nair, ${ }^{1}$ Samuel Abuaf Kohen (D) ${ }^{2}$
}

- Additional material is published online only. To view please visit the journal online (http://dx.doi.org/10. 1136bmjqs-2018-009066).

${ }^{1}$ Institute on Aging \& Lifelong Health, University of Victoria, Victoria, British Columbia, Canada

${ }^{2}$ Intensive Care Unit, Comox Valley Hospital, Courtenay, British Columbia, Canada

\section{Correspondence to} Dr Samuel Abuaf Kohen, Intensive Care Unit, Comox Valley Hospital, Courtenay, BC V9N 0B9, Canada; samuel.kohen@viha.ca

Received 6 November 2018 Revised 7 March 2019 Accepted 23 April 2019 Published Online First 14 June 2019

\section{Check for updates}

(C) Author(s) (or their employer(s)) 2019. Re-use permitted under CC BY-NC. No commercial re-use. See rights and permissions. Published by BMJ.

To cite: Nair R, Kohen SA. BMJ Qual Saf

2019;28:887-893

\begin{abstract}
Background Patients and their families often have an inadequate understanding of the risks and benefits of their advance care planning (ACP) options. Improving patients' knowledge of therapeutic interventions allows them to better select treatments they believe are most appropriate for their condition.

Objectives To determine if a video aimed at educating and engaging hospitalised patients on a standardised $\mathrm{ACP}$ order set can improve (1) inpatient understanding of key ACP concepts, (2) ACP documentation within 48 hours of hospital admission, (3) concordance between a patient's expressed and chart-documented care preferences, (4) patient satisfaction with decision-making, and (5) patient's decisional confidence.

Methods A prospective, non-randomised, pre-post intervention study of 252 inpatients in a 215-bed community-based hospital in Comox, British Columbia, Canada.

Results Our video decision support tool was associated with significant improvements in (1) patient understanding of key ACP concepts (70\%-100\%; $\mathrm{p}<0.0001)$, (2) ACP documentation within 48 hours of hospital admission ( $81 \%-92 \% ; p=0.01)$, (3) concordance between patients' expressed wishes and chart documentation (69\%-89\%; $p<0.0001)$, (4) patient satisfaction with decision-making (Canadian Health Care Evaluation Project Lite score: $4.3-4.5, p=0.001$ ), and (5) patient's decisional confidence (patients with no decisional conflict, increased from $72 \%$ to $93 \%$; $\mathrm{p}<0.0001$ ).

Conclusion A 13 min video aimed at educating and engaging inpatients on ACP concepts improved patient understanding of key ACP concepts, rates of ACP documentation and patient satisfaction with decisionmaking.
\end{abstract}

\section{INTRODUCTION}

Despite miraculous medical advances, technology-laden end-of-life (EOL) care is associated with poorer quality of life, lower satisfaction with care, increased family member anxiety and depression, and increased cost. ${ }^{1-4}$ Conflicts around goals of care often arise due to poor communication regarding prognosis and treatment goals, and can lead to unwanted treatment, ${ }^{5}$ family distress and clinician burnout. ${ }^{16}$ Research suggests that hospital-based healthcare providers (HCP) infrequently engage patients and their families in these conversations. ${ }^{2}$ Communication addressing EOL care has therefore been identified as a high priority for quality improvement initiatives. ${ }^{78}$

The DECIsion-making about goals of care for hospitalized meDical patiEnts (DECIDE) study ${ }^{9}$ identified patient and family understanding of the risks and benefits of therapeutic options as a main barrier to advance care planning (ACP). Physician discomfort and time restrictions are also barriers impeding EOL communication and decision-making. ${ }^{9}$ Improving patient knowledge of therapeutic interventions allows patients to decide on treatments they believe are most appropriate for their condition. ACP decision aids help patients by presenting them with information that is easily understood. ${ }^{10}$ Randomised controlled trials of video-based ACP decision aids, ${ }^{11-13}$ and a systematic review of these tools, ${ }^{14}$ suggest that these aids can reduce uncertainty in decision-making, and clarify patients' preferred goals for care, when compared with verbal description alone. However, very few studies have investigated the use of these video aids in patients admitted to an acute care hospital.

Building on work implementing a standardised ACP order set called the 'Medical Order for Scope of Treatment' (MOST), we developed a video to educate inpatients on ACP and MOST concepts. We determine whether its implementation improves (1) patient understanding of key ACP concepts, (2) documentation of orders for life-sustaining treatment, (3) concordance between patients' expressed preferences for care and those 
documented in their chart, (4) patient satisfaction with care, and (5) patients' decisional confidence. We hypothesised that watching the video would improve patients' understanding of key ACP and MOST concepts, documentation of ACP and patients' experiences of care.

\section{METHODS}

\section{Setting and context}

This study was set at St Joseph's General Hospital (SJGH), a 215-bed Vancouver Island Health Authority (VIHA) affiliated community hospital in Comox, BC, Canada. The hospital's catchment population is $\sim 70$ 000 with a mean age of 53.9 years. In June 2016, SJGH replaced the Do Not Resuscitate order with the VIHA-MOST order, a medical order to be placed at the front of every inpatient's chart outlining their choice of, and consent for the use of, life-sustaining treatments (see online supplementary appendix 1). This change was the hospital's response to a health authority-wide policy change aimed at better ensuring adult patient's wishes and/or instructions are acknowledged and respected, and to standardise the Most Responsible Physician's orders regarding resuscitation status and scope of healthcare treatment decisions. The ACP-MOST video was subsequently developed to support this top-down policy change by educating patients on the concepts and terms presented in the VIHA-MOST.

From June 2015 to February 2016, the lead author (SAK) worked with the VIHA-MOST steering committee to review existing goals of care order forms in use in other regions, and adapt them for use at SJGH. The MOST steering committee simultaneously planned a health authority-wide MOST implementation strategy, including a communication plan (emails and presentations to HCPs), the development of supporting documents and materials (lanyards, cue cards, patient information sheets) and the development of an online education module for allied HCPs using the hospital's learning management system. From March to May 2016, the manager of patient flow, and clinical nurse educators, forwarded health authority communications, arranged regular unit-based educational sessions and engaged unit managers. Unit managers asked staff to complete the online education module ( $<45$ min completion time), and answered any questions or concerns. During this period, the lead author (SAK) also presented the VIHA-MOST to all hospital-based physician groups at their quarterly staff meetings $(<45 \mathrm{~min}$ of engage time). In June 2016, SJGH began implementing the policy of placing an MOST at the front of every inpatient's chart. A year later, the ACP-MOST video intervention was conducted.

\section{Video development}

A multidisciplinary focus group reviewed qualitative studies and systematic reviews to identify key ACP
Box 1 Key concepts presented in the $13 \mathrm{~min}$ ACPMOST video

- Introduce advance care planning (ACP) and the Medical Order for Scope of Treatment (MOST).

- Describe the benefit of engaging in ACP and completing an MOST for patients and their families.

- Describe what type of patients was most likely to benefit from engaging in ACP and completing an MOST.

- Explain how patients can change their MOST designation.

- Describe the difference between medical and critical care.

- Identify what type of patients is most likely to benefit from critical care.

- Explain the default level of care for patients who do not complete an MOST.

- Explain what a temporary surrogate decision maker (TSDM) is and how they are appointed.

concepts (box 1) to be addressed in the ACP-MOST video. This group consisted of two social workers, two clinical nurse educators, four physicians (emergency room/geriatrics, family medicine, critical care and palliative care), a care coordinator for assisted dying, a patient advocacy specialist, a video scriptwriter and a professional media services provider. The ACP-MOST video was designed for a culturally diverse Englishspeaking audience. A preliminary ACP-MOST video was viewed by 35 patients and modified to address their concerns and optimise the messaging (https:// vimeo.com/213742266).

A 1-day cafeteria-based information session was held to raise awareness of the ACP-MOST video among SJGH staff. The video was presented to attendees of the SJGH annual general meeting, and made available to HCPs on the VIHA website. ${ }^{15}$

\section{Video intervention}

Eligible participants included adults ( $\geq 18$ years of age) admitted to the intensive care unit (ICU), telemetry, medical or surgical wards. Patients were excluded if they: were expected to die or be discharged in $<48$ hours (determined by approaching the bedside nurse and attending daily rounds), were on isolation for a communicable disease, did not speak English, had a visual or hearing impairment or were admitted for maternity reasons. Participants were approached by a project technician within 24 hours of hospitalisation on their first admission during the study period, and excluded from re-recruitment on subsequent admissions. As the SJGH administration and ethics committee had approved the study, and all HCPs had been informed of the intervention, attending physicians and other HCPs were not required to provide approval for project technicians to approach eligible participants. Patients consenting to participate immediately underwent competency screening by a project technician. This was assessed using the 
Short Portable Mental Status Questionnaire (SPMSQ). Patients scoring $\geq 7$ (indicating normal mental functioning) on the SPMSQ were eligible to participate in this study.

From February to April 2017 participants received usual care (UC) outlined by a hospital policy that recommends admitting physicians discuss goals of care and treatment preferences with their patients within 48 hours of admission, or in response to any significant changes in their patient's clinical condition. From May to August 2017 participants received UC and watched the ACP-MOST video on a tablet device provided by project technicians. During all phases of this study project technicians were instructed not to explain any ACP concepts to patients beyond those needed for consent, but to encourage patients to direct their questions to their admitting physician. We aimed to recruit 40 patients each month. This number was chosen pragmatically, and was dictated by the average number of patients admitted to SJGH on a weekly basis, and the project funding available. Due to financial constraints, project technicians only worked the first 2 weeks of every month, recruiting patients sequentially until each month's recruitment window closed. This study was not designed around achieving a prespecified level of statistical accuracy.

All study participants were interviewed by a project technician at discharge using a data collection package that included: a VIHA-MOST form, a Patient ACP Knowledge Quiz (see online supplementary appendices 1 and 2, respectively), the Canadian Health Care Evaluation Project (CANHELP) Lite Questionnaire ${ }^{16}$ and the Sure of myself, Understand information, Risk/ benefit ratio and Encouragement (SURE) Test. ${ }^{17}$ Total interview time was $\sim 15 \mathrm{~min}$. Following the interview, each participant's chart was reviewed by a project technician, or project manager, to extract demographic data and ACP documentation information.

\section{Outcome measures}

The primary outcome measure was patient ACP knowledge. This was queried using a quiz (the Patient ACP Knowledge Quiz) developed by a committee of clinical nurse educators, social workers and physicians. This quiz consisted of 10 multiple-choice questions on key ACP and MOST concepts. Patients' ACP knowledge was calculated as the percentage of correct responses on this quiz. This quiz was tested on 10 patients before being used in this study.

Secondary outcome measures included: MOST documentation within 48 hours of hospitalisation (based on chart review), rate of concordance between chart-documented MOST and patient-completed MOST (completed during the discharge interview), CANHELP Lite scores and SURE Test score. Patients lacking a chart-documented MOST were assigned ' $\mathrm{C} 2$ ' in accordance with clinical practice. The 21-item CANHELP Lite Questionnaire was designed and validated to evaluate satisfaction with care for older patients with life-threatening illnesses. Using 5-point Likert scales, respondents rate items as $1=$ not at all satisfied; $5=$ completely satisfied. The satisfaction ratings can be averaged to obtain an overall satisfaction score as well as five domain scores (communication and decision-making, illness management, characteristics of doctors and nurses, your involvement and relationship with doctors). The 4-item SURE Test is used to evaluate patient's decisional confidence, ${ }^{17}$ and has been validated among primary care patients. ${ }^{18}$ Among the four items, a response of 'yes' is scored 1 and a response of 'no' is scored 0 ; a summary score of $4 / 4$ indicates the patient has confidence in their ACP decision.

\section{Statistical analysis}

Baseline characteristics were summarised using mean and SD or median and IQRs. T-tests were used for continuous, normally distributed data. Wilcoxon tests were used for continuous non-normally distributed data. $\chi^{2}$ tests were used for discrete data. Fisher's exact tests were used for sparse discrete data. Statistical significance was set to $p<0.05$. All analyses were performed using SAS V.9.4.

\section{RESULTS}

A total of 796 patients were screened for inclusion. Project technicians excluded 231 patients based on the prespecified exclusion criteria; 228 patients declined involvement. Eighty-five patients scored $<7$ on the SPMSQ. The recruitment rate was 45\% (252 enrolled/565 eligible patients approached for consent). Subsequently, data for two patients were excluded for being largely incomplete. The final sample included 108 'usual care' and 142 'video-intervention' participants (250 participants total). The mean participants' age was 69.8 years $(13.8) ; 48 \%$ were female (table 1 ). The UC and video-intervention cohorts did not significantly differ by age, gender, Charlson Comorbidity Index or admitting diagnosis, but differed significantly by admission unit.

\section{Primary outcome: patients' ACP knowledge}

Addition of the ACP-MOST video to UC was associated with a significant increase in inpatients' ACP knowledge (table 2). Specifically, the median score on the Patient ACP Knowledge Quiz increased from $70 \%$ to $100 \%(\mathrm{p}<0.0001)$. Full details of each cohort's performance on each question of the ACP Knowledge Quiz are given in online supplementary appendix 3 . The UC and video-intervention cohorts did not significantly differ in the level of care selected $\left(\chi^{2}\right.$ test, $p=0.90$, see online supplementary appendix 4$)$.

\section{Secondary outcomes}

This study had four secondary outcomes (table 2). Delivery of the ACP-MOST video was associated with 
Table 1 Demographics of patients in the usual care and video-intervention cohorts

\begin{tabular}{|c|c|c|c|c|}
\hline Variable & Total $(n=250)$ & Usual care $(n=108)$ & Video intervention $(n=142)$ & $P$ value \\
\hline Age (years): mean (SD) & $69.8(13.8)$ & $70.4(15.3)$ & $69.4(12.5)$ & 0.56 \\
\hline Gender (female): n (\% female) & $121(48.4)$ & $57(52.8)$ & $64(45.0)$ & 0.23 \\
\hline Charlson Comorbidity Index: median (IQR) & $3(2,4)$ & $3(2,4)$ & $3(2,5)$ & 0.84 \\
\hline Admitting diagnosis: $\mathrm{n}(\%)$ & & & & 0.39 \\
\hline Cancer & $27(10.8)$ & $11(10.2)$ & $16(11.3)$ & \\
\hline Congestive heart failure & $32(12.8)$ & $18(16.7)$ & $14(9.9)$ & \\
\hline COPD & $20(8.0)$ & $8(7.4)$ & $12(8.5)$ & \\
\hline Hypertension & $46(18.4)$ & $20(18.5)$ & $26(18.3)$ & \\
\hline Osteoarthritis & $46(18.4)$ & $23(21.3)$ & $23(16.2)$ & \\
\hline Others & $79(31.6)$ & $28(25.9)$ & $51(35.9)$ & \\
\hline Admission unit ( $\mathrm{n}(\%))$ & & & & 0.007 \\
\hline Telemetry & $16(6.4)$ & $9(8.3)$ & $7(4.9)$ & \\
\hline Intensive care unit & $10(4)$ & $8(7.4)$ & $2(1.4)$ & \\
\hline Medical & $54(21.6)$ & 15 (13.9) & $39(27.5)$ & \\
\hline Surgical & $170(68)$ & $76(70.4)$ & $94(66.2)$ & \\
\hline
\end{tabular}

*Values in bold indicate significant differences at $p<0.05$.

COPD, chronic obstructive pulmonary disease.

a significant increase in MOST documentation within 48 hours of hospital admission (UC $=81 \%$, video intervention $=92 \% ; \mathrm{p}=0.01$ ).

The ACP-MOST video was associated with a significant improvement in the concordance between patients' expressed wishes and those documented in their chart. Complete congruence between patient-completed and chart-documented MOST improved from 69\% to $89 \%$ (UC vs video intervention, $\mathrm{p}<0.0001$ ). With respect to patient satisfaction, there was no change in overall satisfaction with care (median UC overall satisfaction $4.3(4.0,4.7)$ compared with video intervention $4.4(4.1,4.7) ; \mathrm{p}=0.2)$. The ACP-MOST video was, however, associated with an improvement in satisfaction with decision-making (UC median 4.3 $(3.8,4.8)$, video intervention median $4.5(4.3,4.8)$; $\mathrm{p}=0.001)$. The ACP-MOST video was associated with a significant increase in patients' ACP decisional confidence. Specifically, the frequency of patients with no decisional conflict (scores of $4 / 4$ on the SURE Test) increased from $72 \%$ (UC) to $93 \%$ (video intervention), $\mathrm{p}<0.0001$.

\section{Additional analyses}

We analysed our primary and secondary outcomes stratifying by surgical and medical unit admissions (table 2). We were underpowered to detect differences in the ICU ( $\mathrm{n}=10$ total patients) and telemetry units $(\mathrm{n}=16$ total patients). Notably, implementation of the ACP-MOST video was associated with a significant improvement in all outcomes for surgical unit patients. In both medical and surgical unit patients, implementation of the ACP-MOST video was associated with improvement in the primary outcome, patients' ACP knowledge (medical unit 20\% increase, $\mathrm{p}=0.003$; surgical unit $40 \%$ increase, $\mathrm{p}<0.0001)$. Further, among medical and surgical unit inpatients, viewing the ACP-MOST video was associated with a significant increase in confidence around ACP decision-making (medical unit $28 \%$ increase in patients scoring $4 / 4$ on the SURE Test, $\mathrm{p}=0.008$; surgical unit $17 \%$ increase, $\mathrm{p}<0.008)$.

\section{DISCUSSION}

When added to UC, the ACP-MOST video improved inpatients' understanding of key ACP concepts by $30 \%$, suggesting it has utility as an educational resource and engagement tool. We set out to validate the ACP-MOST video for undifferentiated inpatients, but given difficulty recruiting patients in the ICU and telemetry unit, our results should only be generalised to surgical and medical unit inpatients. Project technicians noted that recruiting from the ICU and telemetry was challenging because patients in these units tended to have higher rates of delirium, were often sleeping or too tired to participate, or lacked interest. The impact of the ACP-MOST video on surgical and medical inpatients' understanding of ACP concepts is consistent with prior research showing that video decision support aids can increase outpatients' (most commonly cancer ${ }^{1112}$ and dementia) ${ }^{19}$ and inpatients' (advanced heart failure) $^{13}$ understanding of ACP concepts.

In this study, the majority of patients were recruited from the surgical unit (68\%), followed by the medical unit (22\%) (box 1). Most surgical unit admissions are for elective procedures, for example, a knee replacement, and almost all of these patients are otherwise healthy, recover quickly and are discharged. Medical unit admissions are never elective, and most patients admitted here typically have multiple comorbidities that may delay discharge. Consequently, the surgical 
unit has higher patient turnover, and on average healthier patients. This likely explains differences in recruitments from these two units. It also explains the high frequency of 'C2' level of care (ie, full critical care including attempting resuscitation) in both the UC and video-intervention cohorts. 'C2' is consistent with an otherwise healthy patient. Arguably, patients admitted to the surgical unit are unlikely to directly benefit from having completed an MOST in the near term. However, this is viewed as an opportunity to engage and socialise patients to ACP concepts long before these important decisions are most likely to matter. Further, some surgical patients (as well as their family and caregivers) do end up benefiting from having completed an MOST.

With regard to secondary outcomes, implementation of the ACP-MOST video improved ACP documentation within 48 hours of hospital admission by $11 \%$, from $81 \%$ to $92 \%(\mathrm{p}<0.01)$. A similar outcome was examined pre-post ACP video implementation at a 276-bed hospital in Hawaii, USA. ${ }^{20}$ In this study, ACP documentation rates for hospitalised patients with late-stage disease increased from 3\% (11/346) to 40\% $(1107 / 2773)(\mathrm{p}<0.001)$ after ACP video implementation. Notably, ACP documentation rates at SJGH were much higher than in Volandes et al's ${ }^{20}$ study, even before video implementation. This could be due to the recent implementation of the VIHA-MOST at SJGH, and the accompanying education and awareness campaign targeted at HCPs. ACP-MOST video implementation also improved the concordance between patients' expressed wishes and those documented in their chart. Prior to video implementation these matched only $69 \%$ of the time; after implementation they matched $89 \%$ of the time. While the rate of ACP documentation speaks to the degree of patient ACP engagement, concordance speaks to the quality of this engagement. High rates of ACP documentation are worthless if concordance is not also high. The fact that the ACP-MOST video nearly eliminates discordance between patient wishes and documented goals of care is critically important. This result reflects a marked improvement on concordance rates reported in previously published studies. ${ }^{8} 21$ While overall patient satisfaction as measured using CANHELP Lite did not change in the video-intervention cohort, for the four questions relating to communication and satisfaction with decision-making, we observed a significant improvement. Other interventions aimed at improving ACP engagement between patients and HCPs, though not video based, also improved patient satisfaction metrics. ${ }^{22}$ Finally, patients showed improvements in the decision-making process with the addition of the ACP-MOST video. Studies have shown that when decisional conflict is high, patients are more likely to delay decision-making, express regret with their decision and blame their physician for bad outcomes. ${ }^{11}{ }^{12}$ This stresses the importance of simplifying and/or assisting 
patients in the decision-making process, and our video appears to do that.

Future implementation strategies for sustaining and spreading use of the ACP-MOST video include: making the ACP-MOST video available on the hospital's television system, adding cues to the admission packages for nurses (ie, instructing nurses to call patients' attention to the ACP-MOST video), and creating pamphlets providing instructions on how to access the ACP-MOST video in hospital and via the internet for patients, family and caregivers. Importantly, these intervention strategies are independent of a project technician, are easily integrated into existing processes of care using infrastructure already in place and require very little additional time from HCPs, making the ACP-MOST video time effective and cost-effective. Future assessment of these implementation strategies should be based on hospital administrative data, and focus on ACP completion rate and level of care selected.

Our study has a several methodological limitations. First, only half of the eligible patients consented to participate in our study, raising the possibility of a selection bias that may limit the generalisability of our results. Second, as an uncontrolled before-and-after study, we cannot account for background factors (eg, other changes occurring concurrently in the hospital or in patients' lives) that may explain the observed differences in outcomes, irrespective of the ACP-MOST video interventions. For example, increasing HCP and patient awareness of the VIHA-MOST, irrespective of the ACP-MOST video, or seasonal changes in healthcare use. Third, there were unanticipated differences in patient recruitment by hospital admission unit, with very few patients recruited from the ICU ( $\mathrm{n}=10$ total) and telemetry $(\mathrm{n}=16$ total) units. While we aimed to validate the ACP-MOST video for all inpatients, some units were insufficiently sampled. Finally, we were unable to find an independently validated ACP knowledge assessment quiz for patients, and therefore developed and administered our own unvalidated tool. Given our study design (comparing cohort) and primary outcome results (indicating sufficient variation in responses) we feel that this methodological limitation did not prevent us from answering our key questions. This study's strengths include its clinically relevant results, positive patient response to the ACP-MOST video, use of validated assessment tools where possible (CANHELP Lite, SURE Test) and rigorous data collection processes.

\section{CONCLUSION}

This study supports the hypothesis that an educational/engagement video can be used to improve inpatients' understanding of ACP concepts. Hospitals interested in improving patient engagement in ACP are welcome to show patients the ACP-MOST video or develop one of their own, drawing on the results of this study. Future research may include tracking uptake of the ACP-MOST video and studying the impact on patient and healthcare system outcomes using administrative data (addressing selection bias), validating the ACP-MOST video for outpatients and further investigating the ACP-MOST video's impact on concordance, in terms of patients' expressed wishes and documented wishes, and actual care delivered over multiple admissions.

Contributors RN and SAK led the study. SAK acquired funding, designed the study and aided in implementation. RN assisted in study design, oversaw implementation and managed the project's daily operations. RN and SAK wrote and revised the manuscript.

Funding The study was funded by BC Special Services Committee, Comox Valley Division of Family Practice, Comox Valley Healthcare Foundation and St Joseph's General Hospital Auxiliary.

Competing interests None declared.

\section{Patient consent for publication Obtained.}

Ethics approval The SJGH administration and ethics committee approved the study.

Provenance and peer review Not commissioned; externally peer reviewed.

Data sharing statement All data relevant to the study are included in the article or uploaded as supplementary information.

Open access This is an open access article distributed in accordance with the Creative Commons Attribution Non Commercial (CC BY-NC 4.0) license, which permits others to distribute, remix, adapt, build upon this work noncommercially, and license their derivative works on different terms, provided the original work is properly cited, appropriate credit is given, any changes made indicated, and the use is noncommercial. See: http://creativecommons.org/licenses/by-nc/4. $0 /$.

\section{ORCID ID}

Samuel Abuaf Kohen http://orcid.org/0000-0003-2063-9007

\section{REFERENCES}

1 Visser M, Deliens L, Houttekier D. Physician-related barriers to communication and patient- and family-centred decisionmaking towards the end of life in intensive care: a systematic review. Crit Care 2014;18.

2 You JJ, Fowler RA, Heyland DK, et al. Just ask: discussing goals of care with patients in hospital with serious illness. Can Med Assoc J 2014;186:425-32.

3 Zhang B, Wright AA, Huskamp HA, et al. Health care costs in the last week of life: associations with end-of-life conversations. Arch Intern Med 2009;169:480-8.

4 Heyland DK, Dodek P, You JJ, et al. Validation of quality indicators for end-of-life communication: results of a multicentre survey. Can Med Assoc J 2017;189:E980-E989.

5 Heyland DK, Ilan R, Jiang X, et al. The prevalence of medical error related to end-of-life communication in Canadian hospitals: results of a multicentre observational study. BMJ Qual Saf 2016;25:671-9.

6 Redinbaugh EM, Schuerger JM, Weiss LL, et al. Health care professionals' grief: a model based on occupational style and coping. Psycho-Oncology 2001;10:187-98.

7 Heyland DK, Cook DJ, Rocker GM, et al. Defining priorities for improving end-of-life care in Canada. Can Med Assoc J 2010;182:E747-E752. 
8 You JJ, Dodek P, Lamontagne F, et al. What really matters in end-of-life discussions? perspectives of patients in hospital with serious illness and their families. Can Med Assoc J 2014;186:E679-E687.

9 You JJ, Downar J, Fowler RA, et al. Barriers to goals of care discussions with seriously ill hospitalized patients and their families: a multicenter survey of clinicians. JAMA Intern Med 2015;175:549-56.

10 Aslakson RA, Schuster ALR, Lynch TJ, et al. Developing the Storyline for an advance care planning video for surgery patients: patient-centered outcomes research engagement from Stakeholder Summit to state fair. J Palliat Med 2017.

11 El-Jawahri A, Podgurski LM, Eichler AF, et al. Use of video to facilitate end-of-life discussions with patients with cancer: a randomized controlled trial. JCO 2010;28:305-10.

12 Volandes AE, Paasche-Orlow MK, Mitchell SL, et al. Randomized controlled trial of a video decision support tool for cardiopulmonary resuscitation decision making in advanced cancer. JCO 2013;31:380-6.

13 El-Jawahri A, Paasche-Orlow MK, Matlock D, et al. Randomized, controlled trial of an advance care planning video decision support tool for patients with advanced heart failure. Circulation 2016;134:52-60.

14 Jain A, Corriveau S, Quinn K, et al. Video decision aids to assist with advance care planning: a systematic review and meta-analysis. BMJ Open 2015;5:e007491.

15 Vancouver Island Health Authority. Most information for health care providers. Secondary most information for health care providers, 2017. Available: https://www.islandhealth. ca/learn-about-health/planning-health-problems/mostinformation-health-care-providers

16 Heyland DK, Jiang X, Day AG, et al. The development and validation of a shorter version of the Canadian health care Evaluation Project questionnaire (CANHELP Lite): a novel tool to measure patient and family satisfaction with end-of-life care. J Pain Symptom Manage 2013;46:289-97.

17 Légaré F, Kearing S, Clay K, et al. Are you sure?: assessing patient decisional conflict with a 4-item screening test. Can Fam Physician 2010;56:e308-14.

18 Ferron Parayre A, Labrecque M, Rousseau M, et al. Validation of SurE, a four-item clinical checklist for detecting decisional conflict in patients. Medical Decision Making 2014;34:54-62.

19 Hanson LC, Zimmerman S, Song M-K, et al. Effect of the goals of care intervention for advanced dementia: a randomized clinical trial. JAMA Intern Med 2017;177:24-31.

20 Volandes AE, Paasche-Orlow MK, Davis AD, et al. Use of Video Decision Aids to Promote Advance Care Planning in Hilo, Hawai'i. J Gen Intern Med 2016;31:1035-40.

21 Heyland DKet al. Failure to engage hospitalized elderly patients and their families in advance care planning. JAMA Intern Med 2013;173:778-87.

22 Detering KM, Hancock AD, Reade MC, et al. The impact of advance care planning on end of life care in elderly patients: randomised controlled trial. BMJ 2010;340:c1345.

23 Tierney WM, Dexter PR, Gramelspacher GP, et al. The effect of discussions about advance directives on patients' satisfaction with primary care. J Gen Intern Med 2001;16:32-40. 